\title{
Due to Instability Gambling is the best Model for most Financial Products
}

\author{
Galiya Klinkova \\ Universidad Nacional de Educación a Distancia, Madrid, Spain; \\ Michael Grabinski \\ Neu-Ulm University, Neu-Ulm, Germany;
}

\begin{abstract}
In financial markets the demand curve is positively sloped in most cases. We give a rigorous mathematical prove that this leads to an instable equilibrium price. Therefore stock prices may fluctuate chaotically, making them unpredictable in many cases. Financial investments have therefore lots in common with gambling. In order to take the analogy further, we suggest a special gambling strategy (betting on a color in roulette). In doing so we have a model which may create a substantial amount of cash each year until it crashes after many years. Both gambling and financial speculation will never create money in the very long run. Because our gambling model is at least statistically predictable, it is "better" than speculative investment.
\end{abstract}

Keywords: stock market; gambling; stability; chaos.

\section{INTRODUCTION}

Though trading in financial markets may involve some speculation, it is by and large considered a necessity for a modern economy. It is even thought to be so essential that some banks are considered too big to fail. On the contrary is the image of gambling. It is maybe entertaining, but it is (sometimes) addictive and by and large considered bad. It is considered so bad that it is illegal in many places.

So far for the common believe. Unfortunately it is a fairy tale. We can show that financial trading is identical to gambling (at least in most cases). In [1] the consequences for the taxation especially the Tobin tax have been shown. Here we start our proof by considering supply and demand curves like in Figure 1. If supply is lower than demand, there is a shortage and prices go up. If supply is higher than demand, there is a surplus bringing prices down. This is the main argumentation for a (stable) market price $\mathrm{p}_{\mathrm{m}}$. In contrast financial products are mostly bought in order to sell them for a higher price. Therefore rising prices make them more attractive. This fundamental difference to ordinary products have also be noted by philosophers, e.g. [2].

Here we give a rigorous proof that financial products never have a stable market price. Because market prices of financial product are very different from the underlying conserved value [3], their value may fluctuate chaotically in a mathematical sense. Therefore financial trading is as unpredictable as gambling.

In our third chapter we will take this analogy further. By introducing a roulette strategy where one is betting on color and doubling the investment until one wins, we have a perfect model for an investment bank. We even conclude in our fourth chapter that real gambling would be less risky than financial trading because a global crisis would be impossible. 


\section{The mechanism of market equilibrium}

In probably any undergraduate course of economics one will learn about supply and demand. In Figure 1 it is shown that the demand will go down, if the price goes up. On the supply side the supplier is happy to offer more, if the price is high. Mathematically spoken the demand

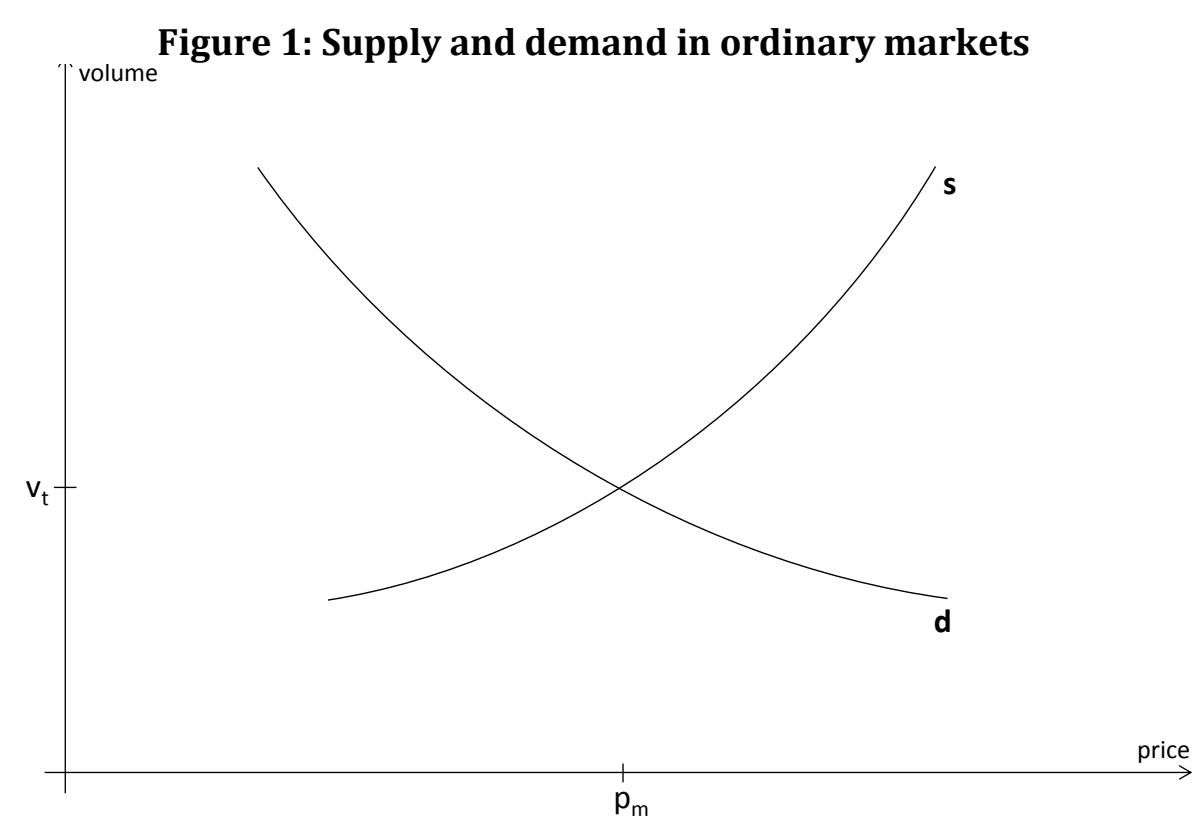

curve (denoted by d in Figure 1) is negatively sloped, and the supply curve (denoted by s in Figure 1) is positively sloped. Therefore they have an intersection. This point defines the market price $\mathrm{p}_{\mathrm{m}}$ and the corresponding traded volume $\mathrm{vt}_{\mathrm{t}}$

Please note that the curves in Figure 1 do not mean that a certain amount of people are buying or selling at particular prices. At a price p, a certain amount of people are willing to sell or buy. The corresponding volume $\mathrm{v}$ is the accumulated volume being traded by these people. Of course, if there is a market price, everybody is buying and selling at that price. If the price $p>$ $\mathrm{p}_{\mathrm{m}}$, there is much more supply than demand. The price goes down. If the price $\mathrm{p}<\mathrm{p}_{\mathrm{m}}$ there is more demand than supply, and the price goes up.

Financial products such as stocks or options have also demand and supply. There is however a difference to almost all other products and services. Most people buy financial products in order to sell them for a higher price. Therefore a rising price is attractive for potential buyers. In other words the demand curve is positively sloped. This difference has been used to explain the momentum effect in stock markets [4]. It has been identified as the main problem in financial markets [2]. While it is obvious that a positively sloped demand curve will not lead to more stability, it is not obvious that it must lead to instability. 
Figure 2: Supply and demand in a financial market

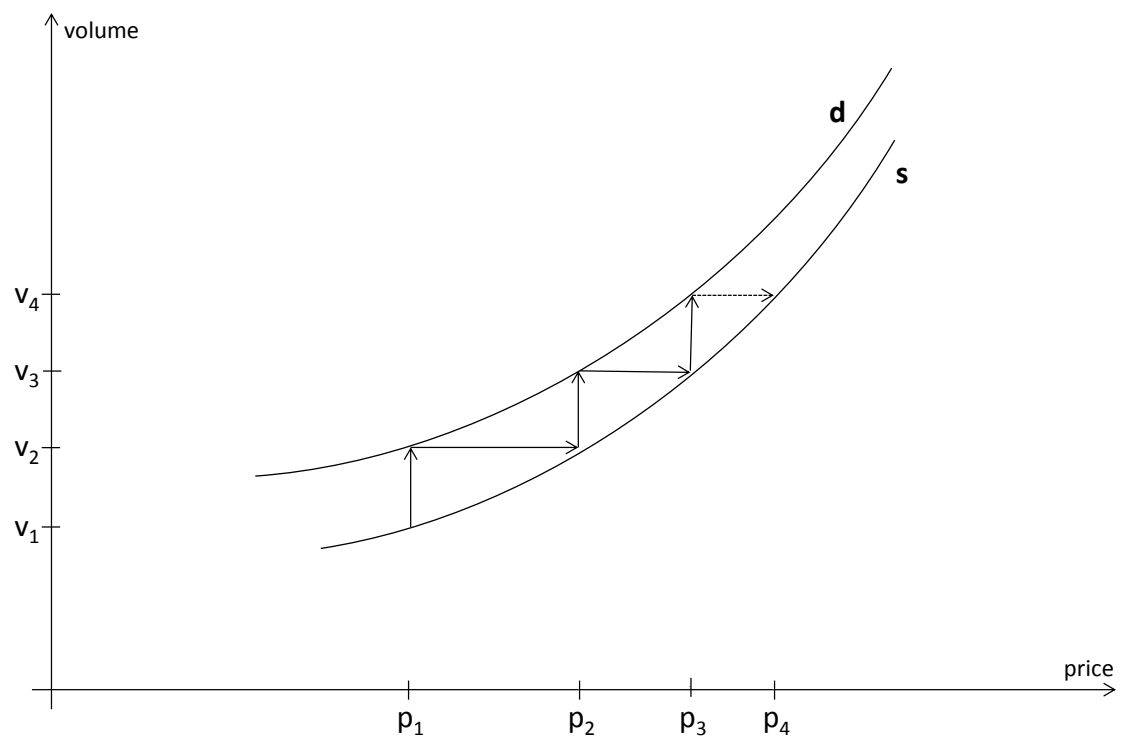

Figure 3: Realistic demand curve in financial markets

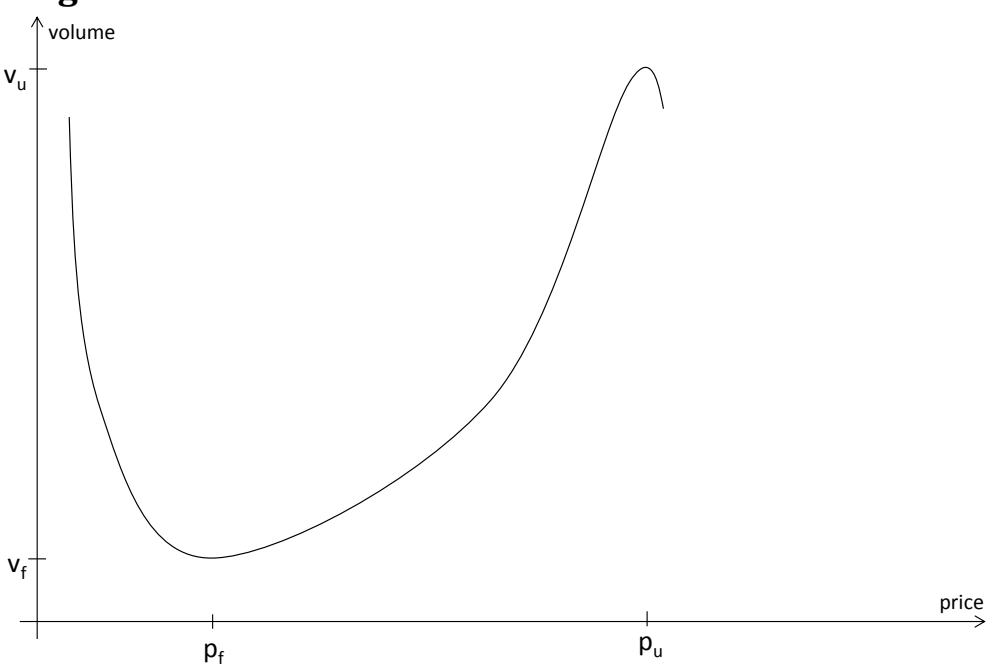

To see the point one may consider the curves in Figure 2. (In financial products the supply curve may have any slope. But it does not change our line of argumentation) Starting with $\mathrm{p}_{1}$ in Figure 2 selling at particular prices. At a price p, a certain amount of people are willing to sell or buy. The selling at particular prices. At a price p, a certain amount of people are willing to sell or buy. The there is too little supply or too much demand. Therefore the price will go up to $\mathrm{p}_{2}$. But the volume v2 is still too small. So the price will go to $\mathrm{p}_{3}$ and so forth. It will spiral upward. If one exchanges s- and d-curve in Figure 2, the price will spiral downward. This is a good indicator for chaotic behavior, but it is no proof for instability. Nevertheless there may be points where supply meets demand. It is even quite likely by considering more realistic demand curves. In Figure 3 it is shown that the demand it not ever increasing with rising prices. At some point the price becomes ridiculously high $\left(\mathrm{p}=\mathrm{p}_{\mathrm{u}}\right)$. A typical point for a so called maidens' hausse. In the same token at a point $\mathrm{p}<\mathrm{p}_{\mathrm{f}}$ the price looks like a super sale (If the price is lower than e.g. book value). With a demand curve of Figure 3 it looks very likely that the supply curve will intersect the demand curve maybe even several times. So we are back to the question whether that market price is stable. In what follows we will prove instability in a mathematically sense.

Please note that the "standard" proof for stability for ordinary markets does not work here. Unfortunately this "standard" proof isn't common knowledge at all. For more detail please see 
[5]. In any market the buyer will pay the market price $p_{m}$ if its value is at least slightly higher. (The value is normally not very much higher, because otherwise competition will be high)

$$
p_{m 0} \precsim \text { value }_{0}
$$

Equation (1) holds for any market transaction. The only specialty for financial markets is that the value is normally not conserved here, cf. [3]. While a conserved value is pretty fixed, a nonconserved one may vary rapidly. The conserved value of e.g. a stock will be proportional to the future earnings a company will make. Though it is not known when buying a stock, it cannot change on a daily basis let alone within milliseconds during high frequency trading. In reality stocks are almost never bought in order to realize the conserved value. In [3] it has been explicitly shown that the market price of a stock is normally several times higher than its underlying conserved value.

The index naught in Equation (1) denotes an initial equilibrium state. It is of course also valid without the naught. Introducing a small variation $\delta p$ with $\mathrm{p}_{\mathrm{m}}=\mathrm{p}_{\mathrm{m} 0}+\delta \mathrm{p}$, inserting it in Equation 1 , and making a Taylor expansion to lowest order leads to:

$$
p_{m 0}+\delta p \precsim \text { value }_{0}+\left.\frac{\partial v a l u e}{\partial p_{m}}\right|_{p_{m 0}} \cdot \delta p+O\left(\delta p^{2}\right)
$$

The immediate learning from Equation (2) is that if the slope $\partial v a l u e / \partial \mathrm{p}_{\mathrm{m}}>1$, positive variations in price $(\delta p>0)$ are only possible in the long run. Else the inequality of Equation (2) does not hold. For a slope $\partial$ value $/ \partial \mathrm{p}_{\mathrm{m}}<1$ the variation in price must be negative for the same reason. This effect can be translated into the timely development of the market price or better traded price. The (non-conserved) value for the buyer does not explicitly depend on time. (Else it would not be possible to choose the starting time as e.g. $\mathrm{t}=0$ ) So we have dvalue/dt $=$ $\partial$ value $/ \partial \mathrm{p}_{\mathrm{m}} \cdot \mathrm{d} \mathrm{p}_{\mathrm{m}} / \mathrm{dt}$. In other words we have:

$$
\frac{\mathrm{dp}_{\mathrm{m}}}{\mathrm{dt}}=\frac{1}{\frac{\partial \mathrm{value}}{\partial \mathrm{p}_{\mathrm{m}}}} \cdot \frac{\mathrm{dvalue}}{\mathrm{dt}}
$$

Equation (3) is the desired change in market price. Because the value is not conserved it may change at any time and in any direction. If $\partial v a l u e / \partial \mathrm{p}_{\mathrm{m}}>1, \delta \mathrm{p}>0$, and the market price will increase slower (in time) than the value for the buyer. So the buyer has even more reason to buy and will do so. The market price will go to infinity. If $\partial v a l u e / \partial \mathrm{p}_{\mathrm{m}}<1, \delta \mathrm{p}<0$, and the market price will decrease faster than the value for the buyer. So it is allowed for the price to become smaller and smaller. Mathematically spoken it will reach minus infinity.

So we have proven that the market price has no stable equilibrium. It will either go to plus infinity or minus infinity. Of course in reality the market price will bounce between $\mathrm{p}_{\mathrm{f}}$ and $\mathrm{p}_{\mathrm{u}}$ of Figure 3 rather than $\pm \infty$.

\section{Gambling: Best Model for financial products}

Market prices in financial markets will either go up or down but will not find (stable) market equilibrium. As seen from Figure 3, volume will also go up with price. This is particularly dangerous in the derivatives market. In an ordinary stock market there is a natural cutoff in 
volume, because the number of stocks is finite (and fix) for a company. Issuing derivatives can be done ad infinitum. It makes the unavoidable crash much more drastic.

While the market price will fluctuate between two extremes, it is far from being predictable. This is because the extreme values denoted by $\mathrm{p}_{\mathrm{f}}$ and $\mathrm{p}_{\mathrm{u}}$ in Figure 3 are neither fixed nor calculable. Especially the upper bound depends on the moods or better nerves of the individual trader. Therefore Saunders [6] found so strange relationships for stock prices as the weather on Wall Street. In other words, nobody can predict stock prices. So it is possible to make a profit, but nobody can plan it. By the way, if stock prices were predictable by any scientific method, it would not last until long, and everybody would use this method. As a result nobody would make a profit. Even in that respect financial trading is identical to gambling. Predicting next week's lottery numbers by whatever method would sooner or later lead to the correct numbers on anybody's lottery ticket. In essence the correct numbers would imply a lower win than the original fee.

Comparing financial trading to gambling or even equating it with it may sound strange for some readers. While financial traders may make a good living over many years, gamblers hardly do. Furthermore profits from financial trading make a substantial part of GDP in some areas. In contrast wins and losses from gambling will make a net loss. However this contradiction is easily solved. In (ordinary) gambling people make a small loss almost all the time. But they have the hope of a rare big win some day. In financial industries it is the other way round. There are some (small) profits over a long period. Then there is a crash or something similar, and all profits of the past are destroyed, cf. [1]. In addition profits from other industries and/or consumers' savings may be taken.

There is however a way of gambling pretty similar to financial trading. It is even performed by some people over their entire life without making any losses. It works as follows. At a roulette table one can bet on red or black. So one may bet $€ 1$ on red. There are two possibilities: Red comes or not. If red comes, one will gain one dollar. If there is black (or zero) one will lose $€ 1$. Then one has to bet $€ 2$ on red (or black). Let suppose one will lose again. So the total loss is $€$ 3. Then one has to bet $€ 4$ on one color. Let suppose one will win now, one will gain $€ 4$. Together with the previous loss of $€ 3$ one will have a net win of $€ 1$. Obviously in one run one will always win $€ 1$, as long as one can afford an arbitrary long row of the wrong color. But even in this limit one will not win anything. Performing the mathematics correctly shows an infinite loss in the limit of infinity. Supposedly there is a limit of playing the game for $\mathrm{n}$ rounds. (For e.g. $n=10$, starting with one dollar would mean taking a maximum bet of $€ 512$ ) Then there is a chance of $(19 / 37)^{\mathrm{n}}$ to lose all the betted money and of course a chance of 1 $(19 / 37)^{\mathrm{n}}$ to win one dollar. (Please note that we are considering the European rather than the American roulette) The average expected gain is therefore

$$
1-\left(\frac{19}{37}\right)^{n}-\left(\frac{19}{37}\right)^{n} \cdot \sum_{i=1}^{n} 2^{i-1}=1-\left(\frac{38}{37}\right)^{n}
$$

As one sees the net gain is always negative. In other words it is a loss. Even or especially in the limit $n$ to infinity it stays negative. It actually goes to $-\infty$. As long as one can afford a high enough bet, one will always have a continuous income for maybe a long time. However, if the desired color does not come for many rounds, the amount for a bet may be higher than the credit line. One is forced to stop with a big loss. This looks familiar to the stock market. 


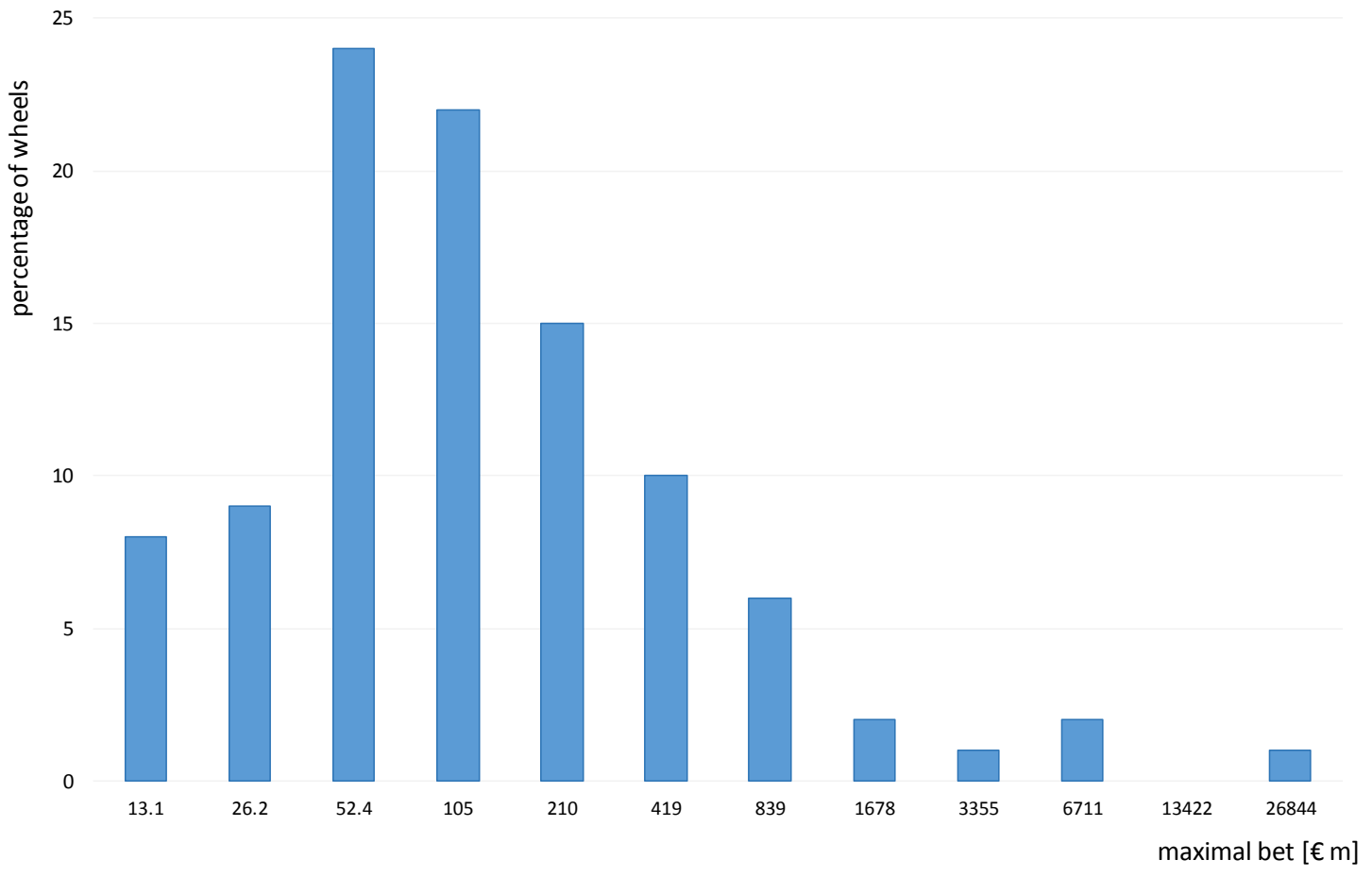

The analogy to the financial industry is even more perfect if one uses proper numbers. Let us suppose our banker/gambler is starting with a bet of $€ 100$. He or she is doing so on 100 roulette tables in parallel. (This is probably easily possible if there are at least 100 online casinos) This is much smarter than starting with €10,000 in the first place, because unlike the worldwide stock markets, 100 roulette wheels are completely independent. So the total risk is correspondingly lower. The outcome from dealing in this way can be calculated by using proper probabilities. For the doubters of statistics, we performed a real experiment. However due to the limits of our grant money, we do it by a computer simulation. Our computer spun 100 wheels for one million times each. Compared to a real roulette it is about ten years of operating each wheel or 1,000 years of spinning one wheel. Pure luck is therefore excluded. In Figure 4 the result of our experiment is shown. If 100 roulette wheels are spun one million times each, within e.g. 15 wheels the necessary maximal bet was $€ 210 \mathrm{~m}$. In only one case a necessary maximal bet of $€ 26.8 \mathrm{~b}$ was necessary. (In our experiment it was wheel number 70, and the maximum was necessary after over 900,000 spins) Including the bets before this maximum, one needs a credit line of $€ 53.7 \mathrm{~b}$. Please note that one does not need such an amount of cash. It is only necessary to have such a credit line. So the five richest men in the world (from Gates to Zuckerberg in 2017) could easily perform our experiment privately. They would have a gross win of $€ 4.86 \mathrm{~b}$ or $€ 486 \mathrm{~m}$ per year. (At least in Germany it would be completely tax free) This is a substantial income for almost no work and no value added to the economy.

\section{CONCLUSIONS}

If the demand curve is positively sloped, the equilibrium price of a stock is not stable. In general it will fluctuate chaotically. Therefore stock prices are not predictable. Betting on them is identical to gambling. As shown in Figure 3 there is maximum price $p_{u}$ and a maximal volume $\mathrm{Vu}$. As bigger as these number get the harder the crash will be. "Normal" stocks have a natural cut-off because $v_{u}$ is limited by the number of stocks issued. Such natural cut-off is not existent 
in derivatives and the like. The market decides how many derivatives are traded. Therefore the derivatives' market is much more speculative. A wisdom known from common sense already.

Investing in something where the outcome is totally uncertain is commonly referred to as gambling. Our special game of betting on a color only, is an almost perfect simulation of a typical stock market. Of course, after a sufficiently long time the model above will fail. If in our case the credit line is not $€ 53.7 \mathrm{~b}$ but just $€ 13.4 \mathrm{~b}$ (the 100 richest men on earth may qualify), one would need a bailout of about $€ 50 \mathrm{~b}$ within a period of ten years for a "company" which produced quite constantly almost $€ 500 \mathrm{~m}$ per year. Also this looks familiar to (investment) banking. Please note that this $€ 50 \mathrm{~b}$ is not gone forever. It can be used to overcome the "financial crisis" (for doubling the last bet). So it may be returned to the tax payer much faster than the bailout money for ordinary financial institutions.

The analogy between (speculative) financial investments and our gambling model goes even further. Within the period between two crashes real money is earned in both cases. One may ask who is paying for these earning? The other participants in the "markets" pay the price! The amount of cash temporarily produced in e.g. computer trading is lost for the millions of ordinary investors. In our gambling model the casino makes less profit. In order to avoid bankruptcy, the casinos are forced to charge higher fees. So the ordinary gambler is slightly less well of.

\section{References}

Dziergwa, K.; Klinkova, G.; Grabinski,M., Why a Financial Transaction Tax will not hurt anybody. The Clute Institute, 2013.

Schefczyk, M. (2012). The Financial Crisis, the Exemption View and the Problem of the Harmless Torturer. in: Philosophy of Management, Special Issue 'Philosophical Lessons from the Global Financial Crisis', Volume 11 (1), 25-38.

Appel, D.; Grabinski, M., The origin of financial crisis: A wrong definition of value, PJQM Vol. 3, 2011.

Appel, D.; Dziergwa, K.; Grabinski, M., Momentum and reversal: An alternative explanation by non-conserved quantities. Int. Jour. Of Latest Trends in Fin. \& Eco. Sc., 2012. 2 (1): p. 8.

Klinkova, G., Chaos effects in business operations from warehouse location to marketing, UNED PhD thesis, 2017.

Saunders, E.M., Stock prices and Wall Street weather, American Economic Review, 2013. 83: p. 1337-1345. 